\title{
Clinicopathological characteristics and survival outcomes in patients with synchronous lung metastases upon initial metastatic breast cancer diagnosis in Han population
}

Shaoyan Lin, Hongnan Mo, Yiqun Li, Xiuwen Guan, Yimeng Chen, Zijing Wang and Binghe Xu*

\begin{abstract}
Background: We investigated the clinicopathological characteristics and survival of breast cancer lung metastases (BCLM) patients at initial diagnosis of metastatic breast cancer (MBC) in the Han population.

Methods: We attained clinical data of 3155 MBC patients initially diagnosed between April 2000 and September 2019 from the China National Cancer Center and finally included 2263 MBC patients in this study, among which 809 patients presented with lung metastases at first MBC diagnosis. The risk factors for BCLM were determined using multivariate logistic regression analysis and the prognostic factors of BCLM patients were assessed by univariate and multivariate Cox regression analyses.

Results: Patients with triple-negative subtype (42.3\%) harbored the highest incidence proportions of lung metastases. Age $\geq 50$ years, Eastern Cooperative Oncology Group (ECOG) 2, M1, hormone receptor-negative (HR-)/human epidermal growth factor receptor 2-positive (HER2) + subtype, triple-negative subtype and disease-free survival (DFS) > 2 years were remarkably associated with higher incidence of lung metastases, while invasive lobular carcinoma (ILC) and bone metastases were significantly correlated with lower odds of lung metastases at diagnosis. The median survival of BCLM patients was 41.7 months, with triple-negative subtype experiencing the worst prognosis of 26.8 months. ECOG 2, triple-negative subtype, liver metastases, multi-metastatic sites and DFS $\leq 2$ years were significantly correlated with poor survival of BCLM patients.
\end{abstract}

Conclusions: Our study provides essential information on clinicopathological features and survival outcomes of BCLM patients at initial diagnosis of MBC in China.

Keywords: Breast neoplasms, Lung, Neoplasm metastasis, Prognosis, Survival

*Correspondence: xubinghe@medmail.com.cn

Department of Medical Oncology, National Cancer Center/National Clinical Research Center for Cancer/Cancer Hospital, Chinese Academy of Medical Sciences \& Peking Union Medical College, No.17, Panjiayuan Nanli, Chaoyang District, Beijing 100021, China

\section{Background}

Lung metastasis is the second most frequent distant metastases of breast cancer [1,2], clinically presenting in $15-25 \%$ of metastatic breast cancer (MBC) patients $[3,4]$. Autopsy data of 197 women dying with MBC over a period of 50 years revealed that $80.7 \%$ of patients had lung or pleura metastases [5]. A population-based study 
indicated that the median survival of 3372 patients with lung metastases at primary breast cancer diagnosis was 21 months [6]. Although the prognosis of MBC patients with metastases confined to lungs is not so poor as brains or livers [7], most patients are considered incurable and the treatment is still intractable. With an occult onset, lung metastases from breast cancer usually present asymptomatically and progress aggressively without appropriate care [8]. Systemic treatments including chemotherapy, targeted therapy and hormone therapy are recommended for patients with breast cancer lung metastases (BCLM) [9] and pulmonary metastasectomy is considerable for properly selected cases [10]. The early detection of lung metastasis and the precise estimation of outcome may benefit breast cancer patients in clinical practice, thus achieving long-term survival. However, the clinicopathological characteristics and the risk factors that affect the incidence and prognosis of BCLM remain poorly identified in the Han population.

In this article, we summarized the clinicopathological features and explored the risk factors associated with the morbidity and mortality of BCLM in newly diagnosed MBC patients in China, which may help identify cases with higher odds of lung metastases and worse survival. Early intervention and multidisciplinary treatment for BCLM patients are of utmost importance.

\section{Methods}

This work was approved by the institutional review board of National Cancer Center/National Clinical Research Center for Cancer/Cancer Hospital, Chinese Academy of Medical Sciences and Peking Union Medical College. All methods were carried out in accordance with relevant guidelines and regulations. The study methods referred to the previous report [11].

\section{Study population}

We attained clinical data of $3155 \mathrm{MBC}$ patients initially diagnosed between April 2000 and September 2019 from the China National Cancer Center database. The database was generated and maintained by medical staff, drawn from the medical records in the hospital information system of China National Cancer Center. Several studies based on this database have been published [11-13]. We removed patients with unknown tumor receptor status $(n=579)$, unknown distant metastases $(n=65)$ and follow-up no more than 1 month since the initial diagnosis of MBC $(n=254)$ from this cohort, finally leaving 2263 patients for incidence analysis. Among these, 809 cases presented with lung metastases (including lymphangitic carcinomatosis and pleural disease) upon initial MBC diagnosis. Lung metastases were identified by enhanced chest CT scan and 220/809 (27.2\%) patients were biopsy proven. Based on the guidelines in our center, lung biopsy was not essential unless the imaging was uncertain. With the improvement of the guidelines, lung biopsy was also considerable for the sake of therapy guidance or patient wishes. Telephone calls or clinical visits were used to follow up patients further to June 30, 2019 or date of their deaths.

\section{Study variables}

Study variables, including age at initial MBC diagnosis, Eastern Cooperative Oncology Group (ECOG) grade, pathological type, TNM stage of primary breast cancer, tumor receptor status, number and type of metastatic sites, disease-free survival (DFS) between primary breast cancer diagnosis and metastatic recurrence, firstline therapy and overall survival (OS) from the onset of metastasis to death were retrospectively collected. DFS was divided as $\leq 2$ years, $>2$ years and patients with de-novo diseases were classified as M1 group. Cancers with $1-100 \%$ estrogen receptor or progesterone receptor routine immunohistochemistry (IHC) staining were considered hormone receptor-positive $(\mathrm{HR}+)$. Human epidermal growth factor receptor 2 (HER2) overexpression was defined as $\mathrm{IHC} 3+$ or in the case of $\mathrm{IHC} 2+$, fluorescent in-situ hybridization (FISH) positive. The HER2 status was determined according to the American Society of Clinical Oncology (ASCO)/College of American Pathologists (CAP) guidelines. Since the ASCO/CAP guidelines have updated across years, the HER2 status was evaluated based on different versions in certain years (2000-2019). The receptor status of metastatic tumors was re-assessed in 512/2263 (22.7\%) cases. Breast cancer subtypes were divided as HR+/HER2-, HR-/HER2+, HR+/HER2+ and triple-negative (HR-/HER2-), based on primary tumor. Tumor staging of the primary tumor was based on the 8th American Joint Committee on Cancer (AJCC) TNM staging system.

\section{Statistical analysis}

Chi-square or Fisher's exact test were used for category variables to compare the clinicopathological features among different subtypes in patients with lung metastases. Incidence of lung metastases was defined as the number of BCLM patients divided by the total number of MBC patients. We performed multivariate logistic regression to explore factors associated with the presence of lung metastases upon initial diagnosis of MBC. We calculated odds ratios (ORs) and 95\% confidence intervals (CIs) in the model. Kaplan-Meier method was utilized to estimate the survival within subsets and log-rank test was used to analyze the differences. We conducted univariate and multivariate Cox regression analyses to investigate the independent predictive factors significantly 
Table 1 Clinicopathological characteristics of patients with lung metastases upon initial metastatic breast cancer diagnosis according to breast cancer subtype

\begin{tabular}{|c|c|c|c|c|c|}
\hline Characteristic & HR+/HER2-, N (\%) & HR-/HER2 +, N (\%) & HR+/HER2+, N (\%) & $\begin{array}{l}\text { Triple-negative, } \\
\mathrm{N}(\%)\end{array}$ & $p$ value \\
\hline All patients & $386(47.7)$ & $116(14.3)$ & $130(16.1)$ & $177(21.9)$ & \\
\hline Age & & & & & 0.015 \\
\hline$<50$ & $172(44.6)$ & $44(37.9)$ & $62(47.7)$ & $99(55.9)$ & \\
\hline$\geq 50$ & $214(55.4)$ & $72(62.1)$ & $68(52.3)$ & $78(44.1)$ & \\
\hline ECOG & & & & & 0.194 \\
\hline 0 & 91 (23.6) & $24(20.7)$ & $23(17.7)$ & $46(26.0)$ & \\
\hline 1 & $278(72.0)$ & $88(75.9)$ & $102(78.5)$ & $117(66.1)$ & \\
\hline 2 & $17(4.4)$ & $4(3.4)$ & $5(3.8)$ & $14(7.9)$ & \\
\hline Pathological type & & & & & 0.552 \\
\hline IDC & $355(92.0)$ & $111(95.7)$ & $125(96.2)$ & $168(94.9)$ & \\
\hline ILC & $9(2.3)$ & $1(0.9)$ & $2(1.5)$ & $3(1.7)$ & \\
\hline Others & $22(5.7)$ & $4(3.4)$ & $3(2.3)$ & $6(3.4)$ & \\
\hline T-stage & & & & & 0.065 \\
\hline $\mathrm{T} 1$ & $104(26.9)$ & $24(20.7)$ & $32(24.6)$ & $47(26.6)$ & \\
\hline $\mathrm{T} 2$ & $169(43.8)$ & $50(43.1)$ & $52(40.0)$ & $83(46.9)$ & \\
\hline $\mathrm{T} 3$ & $20(5.2)$ & $6(5.2)$ & $5(3.8)$ & $17(9.6)$ & \\
\hline $\mathrm{T} 4$ & $18(4.7)$ & $12(10.3)$ & $9(6.9)$ & $6(3.4)$ & \\
\hline Unknown & 75 (19.4) & $24(20.7)$ & $32(24.6)$ & $24(13.6)$ & \\
\hline $\mathrm{N}$-stage & & & & & 0.005 \\
\hline NO & $113(29.3)$ & 25 (21.6) & $30(23.1)$ & $65(36.7)$ & \\
\hline $\mathrm{N} 1$ & $96(24.9)$ & $23(19.8)$ & $43(33.1)$ & $45(25.4)$ & \\
\hline N2 & $66(17.1)$ & $22(19.0)$ & $23(17.7)$ & $31(17.5)$ & \\
\hline N3 & $67(17.4)$ & $35(30.2)$ & $20(15.4)$ & $19(10.7)$ & \\
\hline Unknown & $44(11.4)$ & $11(9.5)$ & $14(10.8)$ & $17(9.6)$ & \\
\hline M-stage & & & & & 0.002 \\
\hline MO & $339(87.8)$ & $88(75.9)$ & $103(79.2)$ & $157(88.7)$ & \\
\hline M1 & $47(12.2)$ & $28(24.1)$ & $27(20.8)$ & $20(11.3)$ & \\
\hline Liver metastases & & & & & 0.001 \\
\hline No & $308(79.8)$ & $85(73.3)$ & $88(67.7)$ & $152(85.9)$ & \\
\hline Yes & $78(20.2)$ & $31(26.7)$ & $42(32.3)$ & $25(14.1)$ & \\
\hline Brain metastases & & & & & 0.625 \\
\hline No & $370(95.9)$ & $108(93.1)$ & $124(95.4)$ & $170(96.0)$ & \\
\hline Yes & $16(4.1)$ & $8(6.9)$ & $6(4.6)$ & $7(4.0)$ & \\
\hline Bone metastases & & & & & $<0.001$ \\
\hline No & $226(58.5)$ & $91(78.4)$ & $89(68.5)$ & $134(75.7)$ & \\
\hline Yes & $160(41.5)$ & $25(21.6)$ & $41(31.5)$ & $43(24.3)$ & \\
\hline Number of metastatic sites & & & & & 0.001 \\
\hline 1 & $104(26.9)$ & $28(24.1)$ & $42(32.3)$ & $53(29.9)$ & \\
\hline 2 & $108(28.0)$ & $48(41.4)$ & $37(28.5)$ & $74(41.8)$ & \\
\hline$\geq 3$ & $174(45.1)$ & $40(34.5)$ & $51(39.2)$ & $50(28.2)$ & \\
\hline Anti-HER2 therapy during first line & & & & & 0.429 \\
\hline Yes & - & $54(46.6)$ & $54(41.5)$ & & \\
\hline No & - & $62(53.4)$ & $76(58.5)$ & & \\
\hline DFS & & & & & $<0.001$ \\
\hline$\leq 2$ years & $83(21.5)$ & $47(40.5)$ & $36(27.7)$ & $94(53.1)$ & \\
\hline$>2$ years & $256(66.3)$ & 41 (35.3) & $67(51.5)$ & 63 (35.6) & \\
\hline M1 & $47(12.2)$ & $28(24.2)$ & $27(20.8)$ & $20(11.3)$ & \\
\hline
\end{tabular}

$H R$ hormone receptor, HER2 human epidermal growth factor receptor 2, ECOG Eastern Cooperative Oncology Group, IDC invasive ductal carcinoma, ILC invasive lobular carcinoma, DFS disease-free survival 
associated with the prognosis of BCLM patients. All the statistics were analyzed using SPSS statistical software version 23.0 package. A two-sided $p$ value of 0.05 or less was significantly different.

\section{Results}

\section{Patient characteristics}

A total of $2263 \mathrm{MBC}$ patients were enrolled in final cohort, of which $35.7 \%$ (809) synchronously presented with lung metastases upon initial MBC diagnosis and Table 1 listed their clinicathological characteristics stratified by breast cancer subtype. It showed that $15.1 \%$ (122) of BCLM patients were diagnosed with de novo metastatic disease (M1). Only 43.9\% (108/246) of BCLM patients with HER2-positive received anti-HER2 therapy during first line. BCLM patients with HR+/HER2-, HR-/ HER2+, HR+/HER2+ and triple-negative subtypes accounted for $47.7,14.3,16.1$ and $21.9 \%$, respectively. Compare with other subsets, triple-negative patients with lung metastases were younger $(p=0.015)$, had an earlier N-stage of primary breast cancer $(p=0.005)$ and a shorter DFS $(p<0.001)$, presented with more recurrent diseases $(p=0.002)$ and less liver metastases $(p=0.001)$. HER2+ (HR-/HER2+ and HR+/HER2+) patients with BCLM were more frequently diagnosed with de novo stage IV breast cancer than HER2- (HR+/HER2- and triple-negative) patients $(p=0.002)$. BCLM patients with HR+/HER2- subtype had the highest rate of bone metastases $(p<0.001)$.

Table 2 displayed the incidence of patients with lung metastases stratified by breast cancer subtype. $\mathrm{HR}+\mathrm{l}$ HER2-, HR-/HER2+, HR+/HER2+ and triple-negative subtypes accounted for $52.1,13.3,16.1$ and $18.5 \%$ of the entire MBC population, respectively. Patients with triplenegative subtype (42.3\%) harbored the highest incidence proportions of lung metastases.

Association between the presence of lung metastases at initial MBC diagnosis and variables assessed by multivariate logistic regression was showed in Table 3 . Age $\geq 50$ years

Table 2 Incidence of patients with lung metastases at first metastatic breast cancer diagnosis stratified by breast cancer subtype

\begin{tabular}{llll}
\hline & $\begin{array}{l}\text { All metastatic } \\
\text { patients, N (\%) }\end{array}$ & $\begin{array}{l}\text { With lung } \\
\text { metastases }\end{array}$ & $\begin{array}{l}\text { Incidence } \\
\text { of lung } \\
\text { metastases, \% }\end{array}$ \\
\hline HR+/HER2- & $1180(52.1)$ & 386 & 32.7 \\
HR-/HER2+ & $300(13.3)$ & 116 & 38.6 \\
HR+/HER2+ & $365(16.1)$ & 130 & 35.6 \\
Triple-negative & $418(18.5)$ & 177 & 42.3 \\
All subtypes & $2263(100.0)$ & 809 & 35.7
\end{tabular}

HR hormone receptor, HER2 human epidermal growth factor receptor 2
Table 3 Multivariate logistic regression for the presence of lung metastases at initial diagnosis of metastatic breast cancer

\begin{tabular}{|c|c|c|}
\hline Characteristic & OR $(95 \% \mathrm{Cl})$ & $p$ value \\
\hline \multicolumn{3}{|l|}{ Age } \\
\hline$<50$ & Reference & \\
\hline$\geq 50$ & $1.29(1.08,1.54)$ & 0.005 \\
\hline \multicolumn{3}{|l|}{ ECOG } \\
\hline 0 & Reference & \\
\hline 1 & $1.16(0.94,1.43)$ & 0.162 \\
\hline 2 & $1.67(1.04,2.67)$ & 0.033 \\
\hline \multicolumn{3}{|l|}{ Pathological type } \\
\hline IDC & Reference & \\
\hline ILC & $0.39(0.22,0.70)$ & 0.002 \\
\hline Others & $1.36(0.81,2.28)$ & 0.241 \\
\hline \multicolumn{3}{|l|}{ T-stage } \\
\hline T1 & Reference & \\
\hline $\mathrm{T} 2$ & $1.07(0.86,1.35)$ & 0.536 \\
\hline T3 & $0.77(0.52,1.14)$ & 0.190 \\
\hline T4 & $1.33(0.84,2.11)$ & 0.223 \\
\hline Unknown & $0.84(0.63,1.12)$ & 0.228 \\
\hline \multicolumn{3}{|l|}{$\mathrm{N}$-stage } \\
\hline NO & Reference & \\
\hline N1 & $1.03(0.81,1.32)$ & 0.787 \\
\hline N2 & $0.99(0.75,1.30)$ & 0.927 \\
\hline N3 & $0.85(0.64,1.13)$ & 0.262 \\
\hline Unknown & $1.08(0.75,1.56)$ & 0.672 \\
\hline \multicolumn{3}{|l|}{ M-stage } \\
\hline MO & Reference & \\
\hline M1 & $1.42(1.05,1.92)$ & 0.022 \\
\hline \multicolumn{3}{|l|}{ Subtype } \\
\hline HR+/HER2- & Reference & \\
\hline HR-/HER2+ & $1.40(1.06,1.85)$ & 0.020 \\
\hline $\mathrm{HR}+/ \mathrm{HER} 2+$ & $1.19(0.92,1.53)$ & 0.188 \\
\hline Triple-negative & $1.63(1.28,2.09)$ & $<0.001$ \\
\hline \multicolumn{3}{|l|}{ Liver metastases } \\
\hline No & Reference & \\
\hline Yes & $0.82(0.66,1.01)$ & 0.067 \\
\hline \multicolumn{3}{|l|}{ Brain metastases } \\
\hline No & Reference & \\
\hline Yes & $1.12(0.72,1.74)$ & 0.608 \\
\hline \multicolumn{3}{|l|}{ Bone metastases } \\
\hline No & Reference & \\
\hline Yes & $0.74(0.61,0.90)$ & 0.002 \\
\hline \multicolumn{3}{|l|}{ DFS } \\
\hline$\leq 2$ years & Reference & \\
\hline$>2$ years & $1.74(1.42,2.14)$ & $<0.001$ \\
\hline M1 & $1.42(1.05,1.92)$ & 0.022 \\
\hline
\end{tabular}


(vs. <50years, $\mathrm{OR}=1.29,95 \% \mathrm{CI}=1.08-1.54, p=0.005$ ), ECOG 2 (vs. ECOG 0, OR=1.67, 95\% CI=1.04-2.67, $p=0.033$ ), $\mathrm{M} 1$ (vs. $\mathrm{M} 0, \mathrm{OR}=1.42,95 \% \mathrm{CI}=1.05-1.92$, $p=0.022$ ), HR-/HER $2+$ subtype (vs. HR+/HER2-, $\mathrm{OR}=1.40,95 \% \mathrm{CI}=1.06-1.85, p=0.020)$, triple-negative subtype (vs. HR+/HER2-, OR $=1.63,95 \% \mathrm{CI}=1.28-2.09$, $p<0.001$ ) and DFS $>2$ years (vs. DFS $\leq 2$ years, $\mathrm{OR}=1.74$, $95 \% \mathrm{CI}=1.42-2.14, p<0.001)$ were remarkably associated with higher incidence of lung metastases at diagnosis. Invasive lobular carcinoma (ILC) (vs. invasive ductal carcinoma (IDC), $\mathrm{OR}=0.39,95 \% \mathrm{CI}=0.22-0.70, p=0.002$ ) and bone metastases (vs. without bone metastases, OR $=0.74,95 \%$ $\mathrm{CI}=0.61-0.90, p=0.002)$ were significantly correlated with lower odds of lung metastases at diagnosis.

\section{Survival}

The median survival among the whole MBC cohort was 45.4 months, with a median follow-up of 61.6 months. Figure 1 showed that the prognosis of patients with lung metastases upon MBC diagnosis (median OS, 41.7 months) was significantly worse than those without lung metastases (median OS, 47.9 months, $p=0.001$ ). Figure 2 provided the survival of BCLM patients according to breast cancer subtype. The survival of BCLM patients with HR+/HER2subtype (49.0months) was the longest, while triple-negative $(26.8$ months, $p<0.001)$ the shortest. BCLM patients with HR-/HER2 + (vs. HR+/HER2-, $p=0.009)$ and HR+/ HER2+ (vs. HR+/HER2-, $p=0.746$ ) subtypes experienced the median OS of 31.6 and 44.1 months, respectively.

The prognostic factors of BCLM patients assessed by univariate and multivariate Cox regression analyses were presented in Table 4 . The significant variables with $p$ value $<0.05$ in univariate analysis were further included in multivariate Cox regression model. ECOG 2 (vs. ECOG 0, $\mathrm{HR}=1.75,95 \% \mathrm{CI}=1.12-2.73, p=0.015$ ), triple-negative subtype (vs. HR+/HER2-, $\mathrm{HR}=1.76$, 95\% $\mathrm{CI}=1.36-2.29, \quad p<0.001$ ), liver metastases (vs. without liver metastases, $\mathrm{HR}=2.19,95 \% \mathrm{CI}=1.70-$ 2.82, $p<0.001$ ), 2 metastatic sites (vs. 1 metastatic site, $\mathrm{HR}=1.76,95 \% \mathrm{CI}=1.34-2.31, p<0.001$ ), and $\geq 3$ metastatic sites (vs. 1 metastatic site, $\mathrm{HR}=1.74,95 \%$ $\mathrm{CI}=1.24-2.44, p=0.001)$ were significantly correlated with poor survival of BCLM patients. DFS $>2$ years (vs. $\mathrm{DFS} \leq 2$ years, $\mathrm{HR}=0.66,95 \% \mathrm{CI}=0.53-0.83, p<0.001)$ predicted favorable prognosis of BCLM patients.

\section{Discussion}

In this retrospective study, we described the clinicopathological characteristics and analyzed the prognosis of patients with synchronous lung metastases at initial MBC diagnosis in China. We identified 809 patients with BCLM upon newly diagnosis of $\mathrm{MBC}$, accounting for

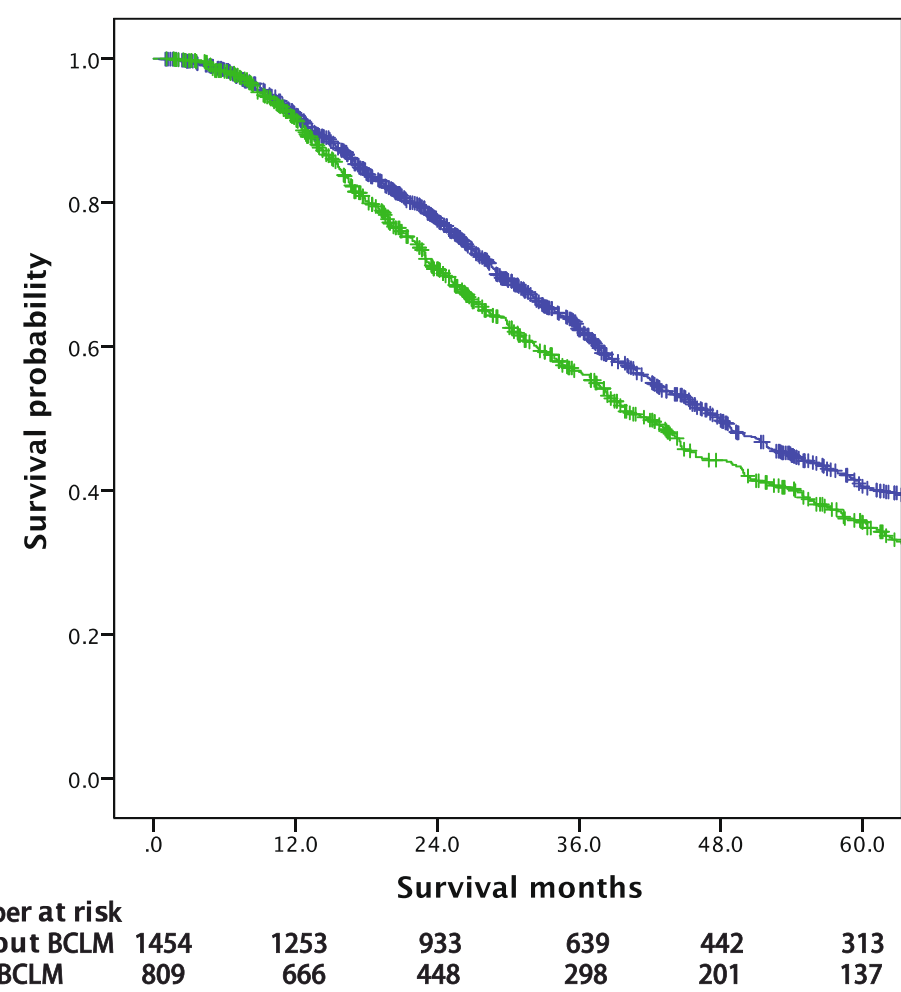

Fig. 1 Overall survival of metastatic breast cancer patients with or without BCLM. BCLM, breast cancer lung metastases 


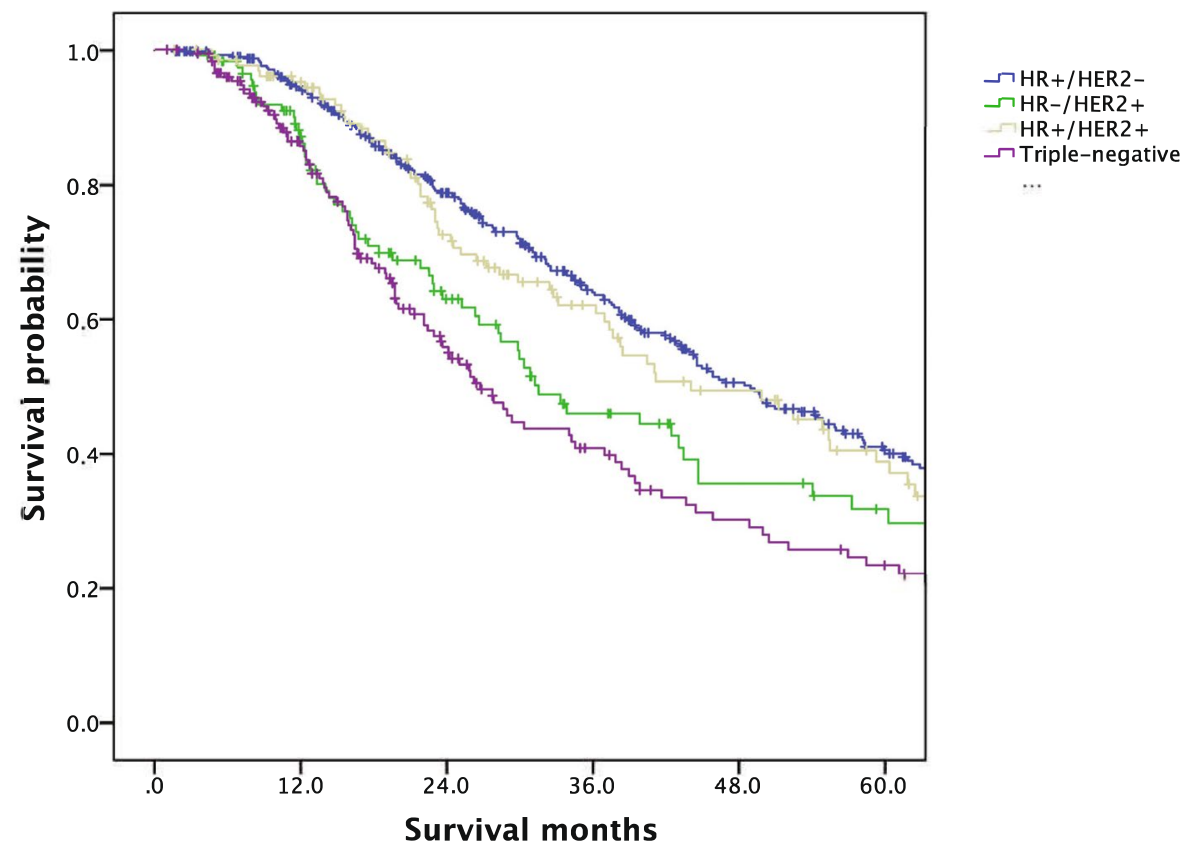

\begin{tabular}{|c|c|c|c|c|c|c|}
\hline \multicolumn{7}{|c|}{ Number at risk } \\
\hline HR+/HER2- & 386 & 335 & 253 & 175 & 118 & 79 \\
\hline HR-/HER2+ & 116 & 89 & 52 & 32 & 20 & 14 \\
\hline $\mathrm{HR}+/ \mathrm{HER} 2+$ & 130 & 114 & 74 & 50 & 36 & 22 \\
\hline TNBC & 177 & 126 & 66 & 40 & 26 & 19 \\
\hline
\end{tabular}

Fig. 2 Overall survival of BCLM patients according to breast cancer subtype. BCLM, breast cancer lung metastases, HR, hormone receptor, HER2, human epidermal growth factor receptor 2, TNBC, triple-negative

$35.7 \%$ of all MBC patients. Compared with other groups, patients with triple-negative subtype had the highest percentage of lung metastases, consistent with previous findings [14-16]. The incidence of lung metastasis in triple-negative breast cancer (TNBC) could reach up to $40 \%$ [17], similar with $42.3 \%$ in our data. Additionally, the prognosis of BCLM patients differed remarkably in tumor subtypes, varying between 26.8 months of triple-negative subtype and 49.0 months of $\mathrm{HR}+\mathrm{l}$ HER2- subtype.

Our study confirmed the results that TNBC was more aggressive and preferred to develop lung metastases. The molecular mechanisms underlying TNBC metastasis to lung might offer therapeutic targets for clinical prevention and management. Minn et al. [18] identified fascin as a mediator promoting basal-like breast cancer metastasis to lung, due to its close association with cell motility. Iriondo et al. [19] observed that inhibition of transforming growth factor- $\beta 1$-activated kinase-1 (TAK1) could suppress lung metastasis in TNBC, which might provide a novel target for impairing TNBC lung metastasis. A single mutation on microrchidia family CW-type zinc finger 2 (MORC2) promoted TNBC lung metastasis by regulating heterogeneous nuclear ribonucleoprotein $\mathrm{M}$ (hnRNPM)- mediated CD44 splicing, which indicated that the knockdown of hnRNPM might reduce lung metastatic potential of TNBC cells with mutant MORC2 [20]. Another research revealed that the overexpression of transcription and export complex 2 subunit (ENY2) could promote TNBC progression and lung metastasis both in vitro and in vivo [21]. Further mechanisms clarifying TNBC lung metastasis are certainly worth exploring, which may provide potential targets for new drugs.

Our data also indicated that patients with older age and worse performance status were more likely to present with lung metastases at initial $\mathrm{MBC}$ diagnosis. The increasing risk of lung metastases associated with aging was consistently found in population-based studies $[6,22]$. On the contrary, previous studies observed that younger patients had a higher risk of liver metastases $[5,23]$. Increased levels of urinary prostaglandin E-metabolite (PGE-M), a biomarker of inflammation, were observed in aging and lung metastases in patients with breast cancer [24]. Levels of multiple proinflammatory mediators, known as inducers of cyclooxygenase-2 (COX-2) and prostaglandin $\mathrm{E}_{2}\left(\mathrm{PGE}_{2}\right)$ synthesis, elevated during aging, which contributed to the increase of PGE-M, a catabolic product of $\mathrm{PGE}_{2}$ [25]. Overexpression of COX-2 in tumor cells within the lung metastases could explain the increased level of 
Table 4 Univariate and multivariate cox regression analyses of OS in BCLM patients

\begin{tabular}{|c|c|c|c|c|c|}
\hline \multicolumn{3}{|l|}{ Univariable analysis } & \multicolumn{3}{|l|}{ Multivariable analysis } \\
\hline Characteristic & Hazard ratio $(95 \% \mathrm{Cl})$ & $p$ value & Characteristic & Hazard ratio $(95 \% \mathrm{Cl})$ & $p$ value \\
\hline Age & & & Age & & \\
\hline$<50$ & Reference & & $<50$ & & \\
\hline$\geq 50$ & $1.04(0.86,1.25)$ & 0.715 & $\geq 50$ & & \\
\hline ECOG & & & ECOG & & \\
\hline 0 & Reference & & 0 & Reference & \\
\hline 1 & $1.23(0.96,1.59)$ & 0.099 & 1 & $1.13(0.87,1.46)$ & 0.351 \\
\hline 2 & $2.62(1.71,4.01)$ & $<0.001$ & 2 & $1.75(1.12,2.73)$ & 0.015 \\
\hline \multicolumn{6}{|l|}{ Pathological type } \\
\hline IDC & Reference & & & & \\
\hline ILC & $0.97(0.53,1.76)$ & 0.912 & & & \\
\hline Others & $0.79(0.49,1.27)$ & 0.324 & & & \\
\hline T-stage & & & T-stage & & \\
\hline $\mathrm{T} 1$ & Reference & & $\mathrm{T} 1$ & Reference & \\
\hline $\mathrm{T} 2$ & $1.17(0.92,1.47)$ & 0.197 & $\mathrm{~T} 2$ & $1.05(0.83,1.34)$ & 0.682 \\
\hline T3 & $1.51(1.01,2.26)$ & 0.044 & $\mathrm{~T} 3$ & $1.10(0.72,1.69)$ & 0.654 \\
\hline T4 & $1.41(0.94,2.11)$ & 0.095 & $\mathrm{~T} 4$ & $1.11(0.70,1.76)$ & 0.654 \\
\hline Unknown & $0.93(0.70,1.24)$ & 0.625 & Unknown & $0.98(0.70,1.37)$ & 0.896 \\
\hline $\mathrm{N}$-stage & & & $\mathrm{N}$-stage & & \\
\hline No & Reference & & No & Reference & \\
\hline $\mathrm{N} 1$ & $1.17(0.90,1.52)$ & 0.241 & $\mathrm{~N} 1$ & $1.05(0.80,1.38)$ & 0.719 \\
\hline N2 & $1.34(1.01,1.77)$ & 0.045 & $\mathrm{~N} 2$ & $1.06(0.78,1.44)$ & 0.708 \\
\hline N3 & $1.79(1.36,2.36)$ & $<0.001$ & N3 & $1.26(0.91,1.74)$ & 0.165 \\
\hline Unknown & $1.19(0.84,1.69)$ & 0.330 & Unknown & $1.01(0.65,1.55)$ & 0.977 \\
\hline \multicolumn{6}{|l|}{ M-stage } \\
\hline MO & Reference & & & & \\
\hline M1 & $1.15(0.89,1.49)$ & 0.296 & & & \\
\hline Subtype & & & Subtype & & \\
\hline HR+/HER2- & Reference & & HR+/HER2- & Reference & \\
\hline HR-/HER2+ & $1.43(1.08,1.90)$ & 0.013 & HR-/HER2+ & $1.35(1.00,1.83)$ & 0.051 \\
\hline $\mathrm{HR}+/ \mathrm{HER} 2+$ & $1.04(0.79,1.37)$ & 0.769 & $\mathrm{HR}+/ \mathrm{HER} 2+$ & $1.04(0.78,1.38)$ & 0.788 \\
\hline Triple-negative & $1.73(1.36,2.19)$ & $<0.001$ & Triple-negative & $1.76(1.36,2.29)$ & $<0.001$ \\
\hline Liver metastases & & & Liver metastases & & \\
\hline No & Reference & & No & Reference & \\
\hline Yes & $2.71(2.20,3.35)$ & $<0.001$ & Yes & $2.19(1.70,2.82)$ & $<0.001$ \\
\hline \multicolumn{6}{|l|}{ Brain metastases } \\
\hline No & Reference & & & & \\
\hline Yes & $1.40(0.94,2.10)$ & 0.100 & & & \\
\hline Bone metastases & & & Bone metastases & & \\
\hline No & Reference & & No & Reference & \\
\hline Yes & $1.43(1.18,1.74)$ & $<0.001$ & Yes & $1.13(0.88,1.44)$ & 0.344 \\
\hline Number of metastatic sites & & & Number of metastatic sites & & \\
\hline 1 & Reference & & 1 & Reference & \\
\hline 2 & $1.86(1.44,2.40)$ & $<0.001$ & 2 & $1.76(1.34,2.31)$ & $<0.001$ \\
\hline$\geq 3$ & $2.42(1.89,3.09)$ & $<0.001$ & $\geq 3$ & $1.74(1.24,2.44)$ & 0.001 \\
\hline DFS & & & DFS & & \\
\hline$\leq 2$ years & Reference & & $\leq 2$ years & Reference & \\
\hline$>2$ years & $0.59(0.48,0.72)$ & $<0.001$ & $>2$ years & $0.66(0.53,0.83)$ & $<0.001$ \\
\hline M1 & $0.81(0.61,1.08)$ & 0.147 & M1 & $0.76(0.55,1.06)$ & 0.105 \\
\hline First-line therapy & & & First-line therapy & & \\
\hline Single-agent chemotherapy & Reference & & Single-agent chemotherapy & Reference & \\
\hline Combination therapy & $0.71(0.47,1.07)$ & 0.099 & Combination therapy & $0.69(0.46,1.05)$ & 0.085 \\
\hline Endocrine therapy & $0.43(0.25,0.75)$ & 0.003 & Endocrine therapy & $0.70(0.39,1.25)$ & 0.223 \\
\hline
\end{tabular}

OS overall survival, BCLM breast cancer lung metastases, Cl confidence interval, ECOG Eastern Cooperative Oncology Group, IDC invasive ductal carcinoma, ILC invasive lobular carcinoma, HR hormone receptor, HER2 human epidermal growth factor receptor 2, DFS disease-free survival 
PGE-M [26]. It's possible that age-related inflammatory conditions mediated breast cancer metastasis to the lung. The predictive features associated with different metastatic sites may help clinicians distinguish patients with distinct organ-specific metastases during the clinical practice.

The BCLM patients in our data achieved a median OS of 41.7 months since $\mathrm{MBC}$ diagnosis, among which triple-negative subtype experienced the worst outcome of 26.8 months and HR+/HER2- subtype the best of 49.0 months. The prognosis of MBC patients varied remarkably by the metastatic organs, with the best for bone, followed by lung, liver and the worst for brain metastases $[7,27]$. Previous findings recorded a survival ranging from 21.0 to 58.5 months in $\mathrm{MBC}$ patients with lung metastases $[1,6,28]$. A pulmonary metastasectomy study reported a median survival of 23.6 months in TNBC patients with an isolated and limited number of lung metastases, significantly poorer than HR+ or HER2+ patients [29]. A population-based research showed that TNBC patients with metastases confined to lung had a median OS of only 14.0 months [30]. TNBC is still lethal and remains intractable to existing treatments, extremely desirable for novel therapies to improve the prognosis.

We also identified prognostic factors for survival of BCLM patients and found that worse performance status, triple-negative subtype, the simultaneous presence of liver metastases, multi-metastatic sites and shorter DFS were significantly correlated with poor outcome. Multiple sites of first metastases had significantly unfavorable prognosis than single site first metastases [31, 32]. In our data, the extrapulmonary metastases had 1.7 times of mortality risk than lung-only metastases at MBC diagnosis. Brain metastases also worsen the outcome of BCLM patients but the difference did not reach significance, probably due to the late onset of brain metastases during the clinical course, with an incidence of only 6.90 to $7.56 \%$ in newly MBC diagnosis patients [32-34]. BCLM patients with DFS shorter than 2 years experienced poorer survival, which indicated the intrinsic aggressiveness of the tumors.

There were some limitations in our study. Firstly, discordance in tumor phenotype has been reported in multiple studies [35], but we did not have enough information on the receptor status of metastatic tumors, which might cause some bias in the analysis of incidence and survival outcomes when stratified by breast cancer subtype. Secondly, the fact that less than half of BCLM patients with HER2-positive received anti-HER2 therapy during first line limits the generalizability of the outcome results. Additionally, the number of lung lesions was an important risk factor for BCLM patients [36], but it was not documented in detail in our database. Finally, the retrospective nature of this research and relatively small population require future studies to confirm the results.

\section{Conclusions}

Our study provides essential information on clinicopathological features and survival outcomes of BCLM patients at initial diagnosis of $\mathrm{MBC}$ in China. The risk factors identified here help to screen breast cancer patients with high odds of lung metastases and BCLM patients with high risk of mortality. The early detection of metastases and proper evaluation of prognosis in clinical practice are beneficial to optimize the disease outcomes.

\section{Abbreviations \\ MBC: Metastatic breast cancer; BCLM: Breast cancer lung metastases; ECOG: East- ern Cooperative Oncology Group; DFS: Disease-free survival; OS: Overall survival; IHC: Immunohistochemistry; HR: Hormone receptor; HER2: Human epidermal growth factor receptor 2; FISH: Fluorescent in-situ hybridization; ASCO/CAP: Ameri- can Society of Clinical Oncology/College of American Pathologists; AJCC: Ameri- can Joint Committee on Cancer; ILC: Invasive lobular carcinoma; IDC: Invasive ductal carcinoma; OR: Odds ratio; Cl: Confidence interval; TNBC: Triple-negative breast cancer; TAK1: Transforming growth factor- $\beta 1$-activated kinase-1; MORC2: Microrchidia family CW-type zinc finger 2; hnRNPM: Heterogeneous nuclear ribonucleoprotein M; ENY2: Transcription and export complex 2 subunit; PGE-M: Prostaglandin E-metabolite; COX-2: Cyclooxygenase-2; $\mathrm{PGE}_{2}$ : Prostaglandin $\mathrm{E}_{2}$.}

\section{Acknowledgements}

Not applicable.

\section{Authors' contributions}

BX directed the study and was responsible for study design. SL performed the statistical analysis and drafted the initial manuscript. All authors collected clinical data. All authors read and approved the final manuscript.

\section{Funding}

This study was supported by grants from National Key R\&D Program of China (2018YFC1312101) and Chinese Academic of Medical Sciences Initiative for Innovative Medicine (CAMS-12 M-1-010).

\section{Availability of data and materials}

The data used during the current study are available from the corresponding author on reasonable request.

\section{Declarations}

Ethics approval and consent to participate

All methods were carried out in accordance with relevant guidelines and regulations. This work was approved by the institutional review board of National Cancer Center/National Clinical Research Center for Cancer/Cancer Hospital, Chinese Academy of Medical Sciences and Peking Union Medical College.

\section{Consent for publication}

The informed consent was obtained from all participants.

Competing interests

The authors declare that they have no competing interests.

Received: 9 July 2021 Accepted: 17 November 2021

Published online: 14 December 2021 


\section{References}

1. Wang R, Zhu Y, Liu X, Liao X, He J, Niu L. The Clinicopathological features and survival outcomes of patients with different metastatic sites in stage IV breast cancer. BMC Cancer. 2019;19:1091.

2. Largillier R, Ferrero JM, Doyen J, Barriere J, Namer M, Mari V, et al. Prognostic factors in 1,038 women with metastatic breast cancer. Ann Oncol. 2008;19:2012-9.

3. Friedel G, Pastorino U, Ginsberg RJ, Goldstraw P, Johnston M, Pass H, et al. Results of lung metastasectomy from breast cancer: prognostic criteria on the basis of 467 cases of the international registry of lung metastases. Eur J Cardiothorac Surg. 2002;22:335-44.

4. Diaz-Canton EA, Valero V, Rahman Z, Rodriguez-Monge E, Frye D, Smith T, et al. Clinical course of breast cancer patients with metastases confined to the lungs treated with chemotherapy. The University of Texas M.D. Anderson Cancer center experience and review of the literature. Ann Oncol. 1998;9:413-8.

5. Cummings MC, Simpson PT, Reid LE, Jayanthan J, Skerman J, Song S, et al. Metastatic progression of breast cancer: insights from 50 years of autopsies. J Pathol. 2014;232:23-31

6. Xiao W, Zheng S, Liu P, Zou Y, Xie X, Yu P, et al. Risk factors and survival outcomes in patients with breast cancer and lung metastasis: a populationbased study. Cancer Med. 2018;7:922-30.

7. Ording AG, Heide-Jørgensen U, Christiansen CF, Nørgaard M, Acquavella J, Sørensen HT. Site of metastasis and breast cancer mortality: a Danish nationwide registry-based cohort study. Clin Exp Metastasis. 2017;34:93-101.

8. Medeiros B, Allan AL. Molecular mechanisms of breast Cancer metastasis to the lung: clinical and experimental perspectives. Int J Mol Sci. 2019;20(9):2272.

9. Cardoso F, Senkus E, Costa A, Papadopoulos E, Aapro M, André F, et al. 4th ESO-ESMO international consensus guidelines for advanced breast Cance (ABC 4)†. Ann Oncol. 2018;29:1634-57.

10. Handy JR, Bremner RM, Crocenzi TS, Detterbeck FC, Fernando HC, Fidias PM, et al. Expert consensus document on pulmonary Metastasectomy. Ann Thorac Surg. 2019;107:631-49.

11. Lin S, Mo H, Li Y, Guan X, Chen Y, Wang Z, et al. Risk factors and survival of patients with liver metastases at initial metastatic breast Cancer diagnosis in Han population. Front Oncol. 2021;11:670723.

12. Li Y, Li Q, Mo H, Guan X, Lin S, Wang Z, et al. Incidence, risk factors and survival of patients with brain metastases at initial metastatic breast cancer diagnosis in China. Breast. 2021:55:30-6.

13. Lin S, Mo H, Li Y, Guan X, Chen Y, Wang Z, et al. Development and validation of a nomogram for predicting survival of advanced breast cancer patients in China. Breast. 2020;53:172-80.

14. Rodríguez-Pinilla SM, Sarrió D, Honrado E, Hardisson D, Calero F, Benitez J, et al. Prognostic significance of basal-like phenotype and fascin expression in node-negative invasive breast carcinomas. Clin Cancer Res. 2006;12:1533-9.

15. Soni A, Ren Z, Hameed O, Chanda D, Morgan CJ, Siegal GP, et al. Breast cancer subtypes predispose the site of distant metastases. Am J Clin Pathol. 2015;143:471-8

16. Jin L, Han B, Siegel E, Cui Y, Giuliano A, Cui X. Breast cancer lung metastasis: molecular biology and therapeutic implications. Cancer Biol Ther. 2018;19:858-68.

17. Foulkes WD, Smith IE, Reis-Filho JS. Triple-negative breast cancer. N Engl J Med. 2010;363:1938-48.

18. Minn AJ, Gupta GP, Siegel PM, Bos PD, Shu W, Giri DD, et al. Genes that mediate breast cancer metastasis to lung. Nature. 2005;436:518-24.

19. Iriondo O, Liu Y, Lee G, Elhodaky M, Jimenez C, Li L, et al. TAK1 mediates microenvironment-triggered autocrine signals and promotes triple-negative breast cancer lung metastasis. Nat Commun. 2018:9:1994.
20. Zhang FL, Cao UL, Xie HY, Sun R, Yang LF, Shao ZM, et al. Cancer-associated MORC2-mutant M276l regulates an hnRNPM-mediated CD44 splicing switch to promote invasion and metastasis in triple-negative breast Cancer. Cancer Res. 2018;78:5780-92.

21. Xie G, Yang H, Ma D, Sun Y, Chen H, Hu X, et al. Integration of wholegenome sequencing and functional screening identifies a prognostic signature for lung metastasis in triple-negative breast cancer. Int J Cancer. 2019;145:2850-60

22. Chen MT, Sun HF, Zhao Y, Fu WY, Yang LP, Gao SP, et al. Comparison of patterns and prognosis among distant metastatic breast cancer patients by age groups: a SEER population-based analysis. Sci Rep. 2017;7:9254.

23. Xie J, Xu Z. A population-based study on liver metastases in women with newly diagnosed breast Cancer. Cancer Epidemiol Biomark Prev. 2019:28:283-92

24. Morris PG, Zhou XK, Milne GL, Goldstein D, Hawks LC, Dang CT, et al. Increased levels of urinary PGE-M, a biomarker of inflammation, occur in association with obesity, aging, and lung metastases in patients with breast cancer. Cancer Prev Res (Phila). 2013:6:428-36.

25. Bruunsgaard $H$, Pedersen $M$, Pedersen BK. Aging and proinflammatory cytokines. Curr Opin Hematol. 2001:8:131-6.

26. Wang D, Dubois RN. Eicosanoids and cancer. Nat Rev Cancer. 2010;10:181-93.

27. Kast K, Link T, Friedrich K, Petzold A, Niedostatek A, Schoffer O, et al. Impact of breast cancer subtypes and patterns of metastasis on outcome. Breast Cancer Res Treat. 2015:150:621-9.

28. Gerratana L, Fanotto V, Bonotto M, Bolzonello S, Minisini AM, Fasola G, et al. Pattern of metastasis and outcome in patients with breast cancer. Clin Exp Metastasis. 2015;32:125-33.

29. Yhim HY, Han SW, Oh DY, Han W, Im SA, Kim TY, et al. Prognostic factors for recurrent breast cancer patients with an isolated, limited number of lung metastases and implications for pulmonary metastasectomy. Cancer. 2010;116:2890-901.

30. Zhao HY, Gong Y, Ye FG, Ling H, Hu X. Incidence and prognostic factors of patients with synchronous liver metastases upon initial diagnosis of breast cancer: a population-based study. Cancer Manag Res. 2018;10:5937-50.

31. Van Mechelen M, Van Herck A, Punie K, Nevelsteen I, Smeets A, Neven P, et al. Behavior of metastatic breast cancer according to subtype. Breast Cancer Res Treat. 2020:181:115-25.

32. Leone BA, Vallejo CT, Romero AO, Machiavelli MR, Pérez JE, Leone J, et al. Prognostic impact of metastatic pattern in stage IV breast cancer at initial diagnosis. Breast Cancer Res Treat. 2017;161:537-48.

33. Martin AM, Cagney DN, Catalano PJ, Warren LE, Bellon JR, Punglia RS, et al. Brain metastases in newly diagnosed breast Cancer: a population-based study. JAMA Oncol. 2017;3:1069-77.

34. Zhao W, Wu L, Zhao A, Zhang M, Tian Q, Shen Y, et al. A nomogram for predicting survival in patients with de novo metastatic breast cancer: a population-based study. BMC Cancer. 2020;20:982.

35. Schrijver W, Suijkerbuijk KPM, van Gils CH, van der Wall E, Moelans CB, van Diest PJ. Receptor conversion in distant breast Cancer metastases: a systematic review and Meta-analysis. J Natl Cancer Inst. 2018;110:568-80.

36. Chen F, Fujinaga T, Sato K, Sonobe M, Shoji T, Sakai H, et al. Clinical features of surgical resection for pulmonary metastasis from breast cancer. Eur J Surg Oncol. 2009:35:393-7.

\section{Publisher's Note}

Springer Nature remains neutral with regard to jurisdictional claims in published maps and institutional affiliations. 